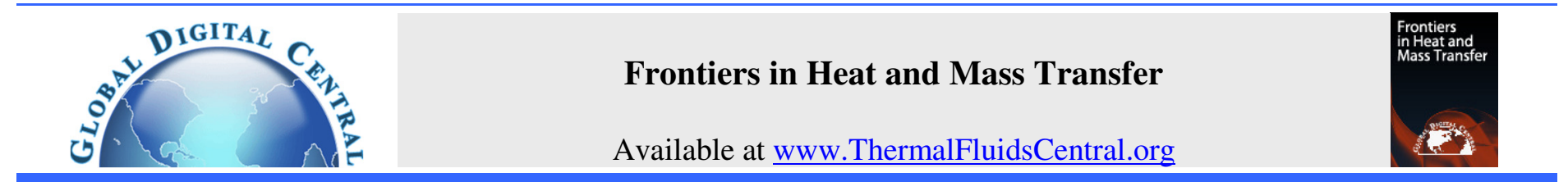

\title{
CORRELATION FOR TURBULENT CONVECTION HEAT TRANSFER IN ELLIPTICAL TUBES BY NUMERICAL SIMULATIONS
}

\author{
Mo Yang ${ }^{a^{*}}$, Xiaoming Wang ${ }^{\mathrm{a}}$, Zhiyun Wang ${ }^{\mathrm{a}}$, Zheng Li ${ }^{\mathrm{b}}$, Yuwen Zhang \\ a School of Energy and Power Engineering, University of Shanghai for Science and Technology, Shanghai, 20093, China \\ ${ }^{b}$ Department of Mechanical \& Aerospace Engineering, University of Missouri, Columbia, Missouri, MO 65211, USA
}

\begin{abstract}
Turbulent convective heat transfer in an elliptical pipe are investigated numerically in this paper. The RSM model is employed in the simulations of elliptical tubes with different aspect ratio a/b and Reynolds numbers within the range of 10,000 120,000. It is found that the maximum deviation between the numerical result and the one from Dittus-Boelter equation contained a hydraulic diameter is $28.4 \%$. Based on simulation results, the correlation between the Nusselt number and Reynolds number in the fully developed fluid section of the elliptical tube is obtained.
\end{abstract}

Keywords: Turbulent flow; the RSM model; maximum deviation; Dittus-Boelter equation

\section{INTRODUCTION}

Forced convection heat transfer in non-circular ducts can find its application in many fields. Dittus-Boelter equation is widely used to calculate the heat transfer coefficient in the non-circular tubes (Batra et al., 1979; Barrow et al., 1985; Colombo et al., 2015; Ragueb et al., 2013). And the hydraulic diameter is used as the characteristic length for the Reynolds number in the Dittus-Boelter equation. However, Malák et al. (1975) studied several kinds of non-circular tubes using experiment method, and demonstrated that it is not accurate to calculate the turbulent convection heat transfer in the non-circular tubes using the hydraulic diameter method. Wang et al. (2014) also showed that this theory through numerical simulation and found that the maximum deviation would be $27.5 \%$ for the square cross-section. Aly et al. (2006) investigated the fully developed air-flows in an equilateral triangular duct over a Reynolds number range of 53,000-107,000, while friction factors were found to be about 6\% lower than for pipe flow. Eckert et al. (1960) reported a numerical simulation of the isosceles triangle pipe with the length ratio of 5 , and found that the coefficient of friction resistance that was calculated by using the hydraulic diameter method resulted in a relative deviation of about $20 \%$. Based on the references above, it can be concluded that it is inaccurate to use the Dittus-Boelter equation to calculate heat transfer of turbulent convection in noncircular pipes.

The elliptical tube, as a typical shaped tube, has many advantages. For example, in the same cross section, more elliptical tubes can be arranged to make the heat exchanger more compact. With the same Reynolds number, the drag coefficient of the elliptical tube which axis ratio is 2 is only about $50 \%$ of the circular tube (Terukazu et al., 1984). Due to these advantages, many scholars have performed a lot of research on elliptical tubes. An experimental study was carried out inside elliptic tube fixed with helical coils by Omara et al. (2018). Hermany et al. (2018) studied convective heat transfer of non-Newtonian fluids over elliptical tubes. And the structured design associated with exhaustive search was employed to obtain the ellipse aspect ratios to maximize the Nusselt number and to minimize dimensionless pressure drop. Paweł et al. (2016) performed experimental and numerical investigations of flow distribution in the heat exchanger with elliptical tubes, while various turbulent modes were compared. Ibrahim et al. (2009) investigated the thermofluid characteristics of the elliptical tube bundle in crossflow. They found that the best thermal performance of the elliptical heat exchanger was achieved with the lower values of Reynolds number, axis ratio and angle of attack. Although various investigations have been performed, no one presented a correction formula of elliptical tube for turbulent convective heat transfer. To fill this gap, we perform numerical investigations for the fluid flow and heat transfer in various elliptical tubes and propose a novel correlation accordingly.

Numerical simulations have been used for different fluid flow and heat transfer problems, and more and more researchers are using this method. For example, Cheng et al. (2017) presented the first direct numerical simulation of a turbulent pipe flow using the mesoscopic Lattice Boltzman method. Qiu et al. developed an unsteady numerical model for double-diffusive natural convection of low Prandtl number liquids with Sored and Dufour effects inside the horizontal cavity. Yang et al. (2017) used the Lattice Boltzman method to miniaturize the natural convection in the horizontal loop. Carrillo et al. (2016) presented a numerical scheme for nonlinear continuity equations, which is based on the gradient flow formulation of an energy functional with respect to the quadratic transportation distance. Li et al. $(2015,2016)$ studied the melting problem and three-dimensional natural convection heat transfer using the Lattice Boltzmann method. Chiappini et al. (2017) presented a comparison between experimental and numerical simulation in opencells metal foams. Ma et al. (2016) analyzed combustion mechanism of a $300 \mathrm{MW}$ pulverized coal boiler and carried out the optimization of the performance of the boiler using numerical simulation. These examples show that the numerical simulation results are reliable and can be used for theoretical research.

Reynolds Stress model (RSM) is employed to investigate the turbulent flow and heat transfer performances in elliptical tubes. Then, the results were obtained by numerical simulation with different axis ratios $\mathrm{a} / \mathrm{b}$ and $N u$ numbers under different working conditions. A new correlation is proposed based on the results of numerical solutions. 


\section{PHYSICAL MODEL AND NUMERICAL METHODS}

\subsection{Physical Model}

The physical model of elliptical tube is shown in Figure 1. The fluid flow direction is perpendicular to the paper. And non-circular pipe hydraulic diameter is $\mathrm{d}=\frac{4 S}{U}$, where $S$ is the cross-sectional area of the channel and $U$ is the wet perimeter. $\mathrm{S}=\pi \mathrm{ab}, \mathrm{U}=2 \pi \sqrt{\frac{a^{2}+b^{2}}{2}}$, where a is the length of semi-major axis and $b$ is the length of semi-minor axis. According to Wang et al. (2014), the tube length $L \geqslant 60 \mathrm{~d}$ can ensure that the fluid in the tube enters the fully developed section. The tube length $\mathrm{L}$ is $100 \mathrm{~d}$ in this article.

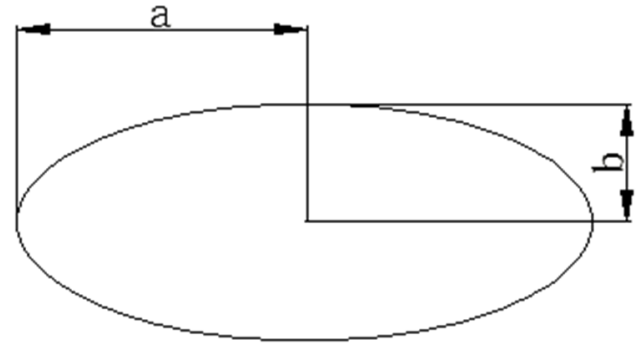

Fig. 1 Schematic of flow section

\subsection{General governing equations}

In this paper, water is used as the working fluid in the simulation with the following assumptions: (1) the fluid in the tube is a Newtonian fluid; (2) the fluid property in the tube remains constant and the fluid is incompressible; (3) effect of gravity can be neglected.

In this paper, the RSM is used for numerical simulation, the governing equation are shown below:

Transport equation:

$$
\frac{\partial}{\partial t}\left(\rho \overline{u_{\imath} u_{\jmath}}\right)+\frac{\partial}{\partial x_{k}}\left(\rho U_{k} \overline{u_{\imath} u_{\jmath}}\right)=D_{i j}+\emptyset_{i j}+G_{i j}-\varepsilon_{i j}
$$

Diffusion term:

$$
\begin{aligned}
& D_{i j}=-\frac{\partial}{\partial x_{k}}\left(\rho \overline{u_{\imath} u_{\jmath} u_{k}}+\overline{p u_{\jmath}} \delta_{j k}+\overline{p u_{\imath}} \delta_{j k}-\mu \frac{\partial}{\partial x_{k}} \overline{u_{\imath} u_{\jmath}}\right) \\
& \text { Pressure strain: }
\end{aligned}
$$

$\emptyset_{i j}=\overline{p\left(\frac{\partial u_{l}}{\partial x_{j}}+\frac{\partial u_{\jmath}}{\partial x_{l}}\right)}$

Generation term:

$G_{i j}=\rho\left(\overline{u_{\imath} u_{k}} \frac{\partial U_{j}}{\partial x_{k}}+\overline{u_{\jmath} u_{k}} \frac{\partial U_{i}}{\partial x_{k}}\right)$

Dissipative term:

$\varepsilon_{i j}=2 \mu \frac{\overline{\partial u_{l}}}{\partial x_{k}} \frac{\partial u_{j}}{\partial x_{k}}$

Energy equation:

$k=\frac{1}{2} \overline{u_{\imath}^{\prime} u_{\imath}^{\prime} \frac{\partial}{\partial t}(\rho k)}+\frac{\partial}{\partial x_{i}}\left(\rho k u_{i}\right)$

$=\frac{\partial}{\partial x_{j}}\left[\left(\mu+\frac{\mu_{i}}{\sigma_{k}}\right) \frac{\partial k}{\partial x_{j}}\right]+\frac{1}{2} P_{i i}-\rho \varepsilon\left(1+2 M_{t}^{2}\right)$

$M_{t}=\sqrt{\frac{k}{\gamma R T}}$

Turbulent viscosity:

$$
\mu_{t}=\rho C_{\mu} \frac{k^{2}}{\varepsilon}
$$

where: $C_{\mu}=0.99$.

Convective heat transfer equation:

$$
\begin{aligned}
& \frac{\partial}{\partial t}(\rho E)+\frac{\partial}{\partial x_{i}}\left[u_{i}(\rho E+p)\right] \\
& =\frac{\partial}{\partial x_{j}}\left[\left(k+\frac{c_{p} \mu_{t}}{P r_{t}}\right) \frac{\partial T}{\partial x_{j}}+u_{i}\left(\tau_{i j}\right)_{e f f}\right] \\
& \left(\tau_{i j}\right)_{e f f}=\mu_{e f f}\left(\frac{\partial u_{j}}{\partial x_{i}}+\frac{\partial u_{i}}{\partial x_{j}}\right)-\frac{2}{3} \mu_{e f f} \frac{\partial u_{k}}{\partial x_{k}} \delta_{i j}
\end{aligned}
$$

where: $P r_{t}=0.85$

Boundary conditions:

All walls are satisfied:

$T_{w}=$ Constant

\subsection{Grid independence verification}

This article simulates the turbulent motion of an elliptical tube. Considering that there is a flow boundary layer and a thermal boundary layer near the wall, the flow characteristics change drastically, so finer mesh is used near the wall surface. In this paper, the RSM model is adopted, and the enhanced wall function is selected. Therefore, the $y^{+}$ wall surface function should be used for processing the wall surface. When generating the grid, it is necessary to arrange the first inner node in the area where the law of logarithm is established, and the grid near the wall needs to satisfy the condition $y^{+} \approx 1 . y^{+}$is a dimensionless parameter that characterizes the distance from the wall to the node. The equation is as follows:

$$
y^{+}=\frac{\rho u_{\tau} y}{\mu}
$$

where: $u_{\tau}=\sqrt{\frac{\tau_{w}}{\rho}}$, and $\tau_{w}$ is near wall shear stress, the equation is:

$$
\tau_{w}= \begin{cases}\frac{2 \mu\left|\bar{u}_{p}\right|}{\Delta y} & \left|\vec{u}_{p}\right| \leq \frac{\mu A^{2 /(1-B)}}{2 \rho \Delta y} \\ \rho\left[\frac{1-B}{2} A^{(1+B) /(1-B)}\left(\frac{\mu}{\rho \Delta y}\right)^{(1+B)}+\frac{1+B}{A}\left(\frac{\mu}{\rho \Delta y}\right)^{B}\left|\bar{u}_{p}\right|\right]^{2 /(1+B)} & \left|\vec{u}_{p}\right|>\frac{\mu A^{2 /(1-B)}}{2 \rho \Delta y}\end{cases}
$$

where: $\bar{u}_{p}$ is the flow velocity near the wall, $\Delta \mathrm{y}$ is the dimension in the $\mathrm{y}$-axis direction of the grid, and $\mathrm{A}$ and $\mathrm{B}$ are constants, $\mathrm{A}=8.3, \mathrm{~B}=1 / 7$.

In the case of $R e=2 \times 10^{4}$, numerical simulations are performed with different grid settings. As shown in Figure 2, the change in the number of nodes of elliptical tube circumference has a great influence on the simulation result. With the increase of the number of nodes, $\mathrm{Nu}$ number also increases. When the number of nodes no longer affects the simulation results. This paper divides the circumference grid into 50 nodes, as shown in Figure 3.

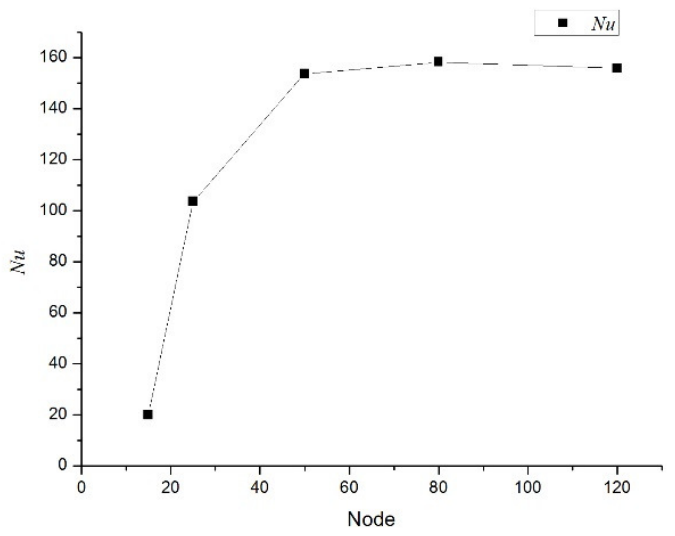

Fig. 2 Change trend of $N u$ along with the change of the number of nodes 


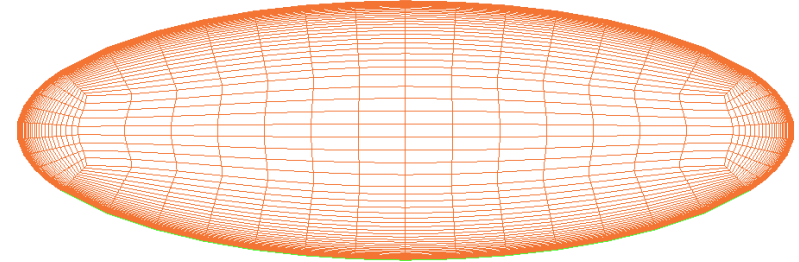

Fig. 3 The grid of an elliptic pipe

\subsection{Numerical methods}

The convection-diffusion term of the QUICK difference scheme is used, and the coupling of pressure and velocity is processed by the SIMPLE method. To verify the numerical method, round tube is solved and results are compared with the Dittus-Boelter equation. It can be seen from Figure 4 that using RSM, the maximum relative deviation between $\mathrm{Nu}$ obtained by simulation and the corresponding empirical Dittus-Boelter equation is $5 \%$, and the degree of coincidence is very good. Therefore, RSM numerical method is valid for this kind of simulation then it is used to study the turbulent convective heat transfer in an elliptical tube.

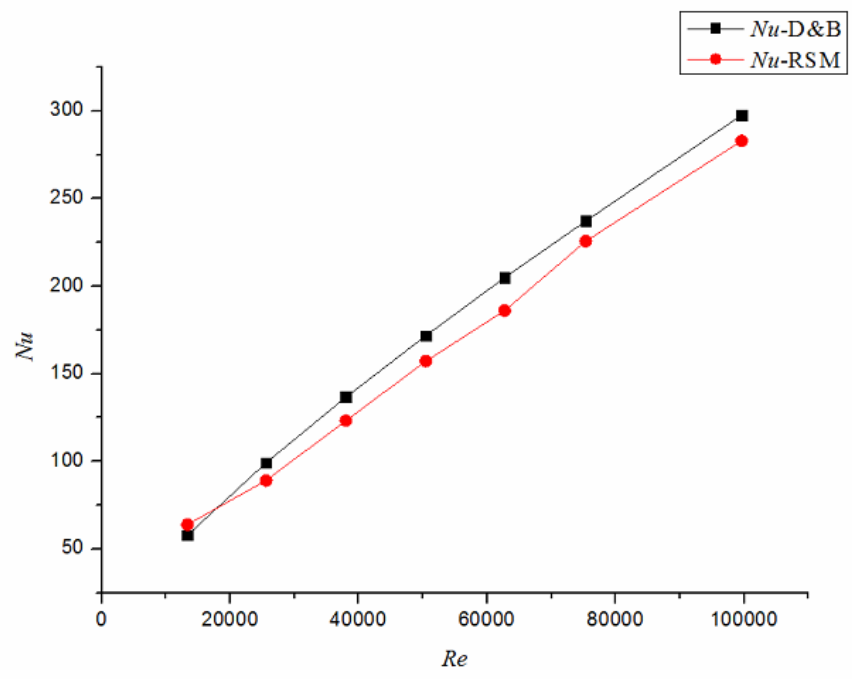

Fig. 4 The verification of RSM numerical method

\subsection{Data processing}

The average temperature of the passage section is:

$$
T_{m}=\frac{\int_{0}^{S} \rho u c_{p} T d S}{\int_{0}^{S} \rho u c_{p} d S}
$$

where $\rho$ is the density of the fluid in the tube, $u$ is the flow velocity of the fluid in the tube, $c_{p}$ is the specific heat of the fluid in the tube, $T$ is the fluid temperature in the tube, and $S$ is the cross-sectional area of the channel.

The local convection heat transfer coefficient $h$ is:

$$
h=\frac{q}{T_{w}-T_{m}}
$$

where $q$ is the heat flux through the wall, and $T_{w}$ is the wall temperature of tube and remains constant.

The local Nusselt number is:

$$
N u=\frac{h d}{\lambda}
$$

where $\lambda$ is the fluid thermal conductivity in the tube.

After the heat transfer of the fluid entering into fully developed region, local $\mathrm{Nu}$ will keep as constant.
In order to ensure heat transfer into the fully developed region, 29 cross-sections are evenly taken in the flow direction of the entire elliptical tube. The section near the entrance to the pipeline is named S1, and the section near the export is named S29. Using Eq. (14-16), local $N u$ of 29 sections are obtained in Figure 5.

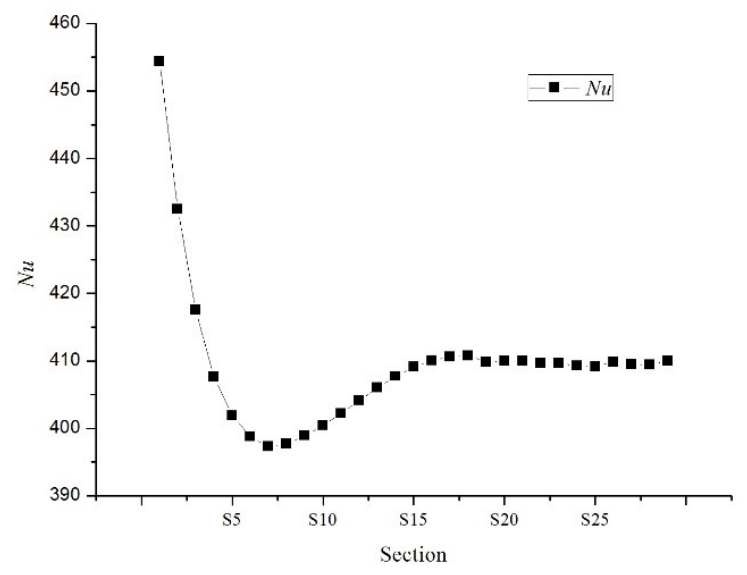

Fig. 5 Local $N u$ of different sections

It can be seen from Figure 5 that local $\mathrm{Nu}$ does not change substantially after the S19 section, which means that the heat transfer goes into the fully developed region. In the following discussion, we only focus on the $\mathrm{Nu}$ of fully developed region.

\section{RESULTS AND DISCUSSIONS}

\subsection{Comparison between results obtained from numerical simulation and Dittus-Boelter equation}

Regarding the applicable range of the Dittus-Boelter equation is $10^{4} \leq$ $R e \leq 1.2 \times 10^{5}$, twelve conditions are selected in this range. When the axis ratio is $3 / 2$, the turbulent convection heat transfer in the elliptical tube is numerically simulated, and its fully developed $N u$ obtained by the Dittus-Boelter equation and simulation are shown in Table 1.

\begin{tabular}{|c|c|c|c|}
\hline \multirow[b]{2}{*}{$R e$} & \multicolumn{2}{|c|}{$\mathrm{Nu}$} & \multirow[b]{2}{*}{$\begin{array}{l}\text { Deviation } \\
\quad(\%)\end{array}$} \\
\hline & $\begin{array}{c}\begin{array}{c}\text { Dittus-Boelter } \\
\text { equation }\end{array} \\
\end{array}$ & $\begin{array}{l}\text { Numerical } \\
\text { Simulation }\end{array}$ & \\
\hline $1 \times 10^{4}$ & 79.4 & 93.1 & 17.3 \\
\hline $2 \times 10^{4}$ & 138.2 & 164.2 & 18.8 \\
\hline $3 \times 10^{4}$ & 191.2 & 224.7 & 17.5 \\
\hline $4 \times 10^{4}$ & 240.7 & 291.1 & 20.9 \\
\hline $5 \times 10^{4}$ & 287.7 & 350.5 & 21.8 \\
\hline $6 \times 10^{4}$ & 332.9 & 409.1 & 22.9 \\
\hline $7 \times 10^{4}$ & 376.6 & 464.9 & 23.4 \\
\hline $8 \times 10^{4}$ & 419.1 & 520.4 & 24.2 \\
\hline $9 \times 10^{4}$ & 460.5 & 574.9 & 24.8 \\
\hline $1 \times 10^{5}$ & 501.0 & 629.1 & 25.6 \\
\hline $1.1 \times 10^{5}$ & 540.7 & 682.3 & 26.2 \\
\hline $1.2 \times 10^{5}$ & 579.6 & 744.2 & 28.4 \\
\hline
\end{tabular}

Table 1 The relative relationship between $N u$ numbers obtained by Dittus-Boelter equation and by simulation in elliptic tube 
From Table 1 and Figure 6, it can be seen that the maximum relative deviation between the Nu number obtained by the simulation and by the Dittus-Boelter equation is $28.4 \%$. It can be seen that, in the calculation of the turbulent convective heat transfer in an elliptical tube, the method of directly substituting the hydraulic diameter into the Dittus-Boelter equation brings a large deviation. Therefore, it is necessary to establish a new correlation for the elliptical pipeline.

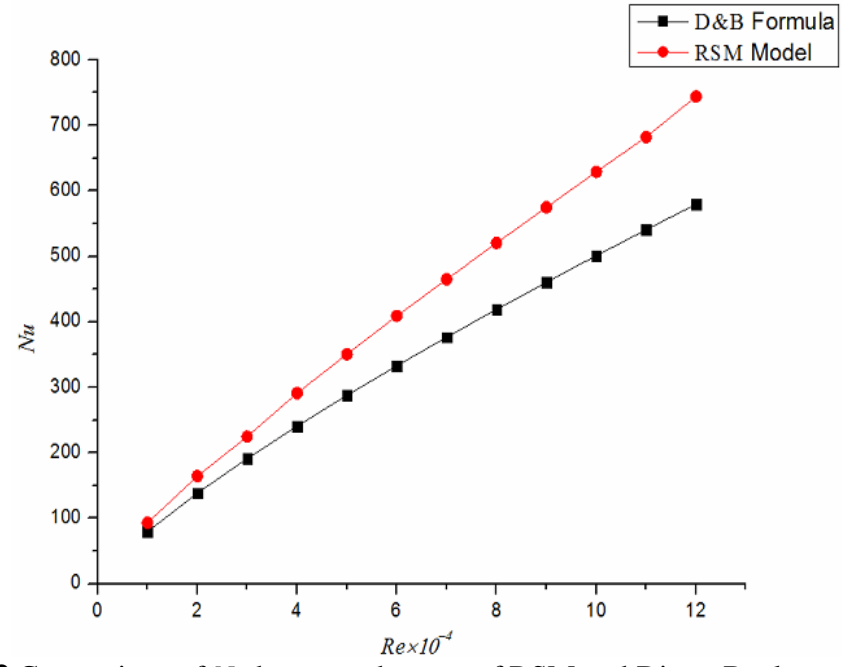

Fig. 6 Comparison of $\mathrm{Nu}$ between the uses of RSM and Dittus-Boelter equation

\subsection{The influence of the axis ratio $\mathrm{a} / \mathrm{b}$ on $\mathrm{Nu}$ number}

In order to explore other factors that may cause deviation between simulation results and the Dittus-Boelter equation results, conditions with different axis ratios are simulated in this paper while keeping the circumference of the pipe cross-section constant. Take $R e=2 \times 10^{4}$, the results are shown in Table 2 .

Table 2 Effects of different a/b numbers on numerical simulation

\begin{tabular}{|c|c|c|c|c|c|c|}
\hline $\mathrm{a} / \mathrm{b}$ & 1.5 & 2 & 2.5 & 3 & 4 & 5 \\
\hline $\mathrm{Nu}$ & 164.2 & 208.9 & 193.7 & 155.1 & 152.9 & 153.9 \\
\hline
\end{tabular}

From Table 2, it can be seen intuitively that under the premise of keeping the heat transfer surface area unchanged, $\mathrm{Nu}$ increases first and then decreases as the axis ratio $\mathrm{a} / \mathrm{b}$ increases, and then remains unchanged. When $\mathrm{a} / \mathrm{b}=2, N u$ increases by $27.23 \%$ compared to $\mathrm{a} / \mathrm{b}$ of 1.5 . This can also further prove that it is not receivable to calculate the turbulent convective heat transfer using the Dittus-Boelter equation.

\subsection{The correlation of turbulence convection in elliptical tube}

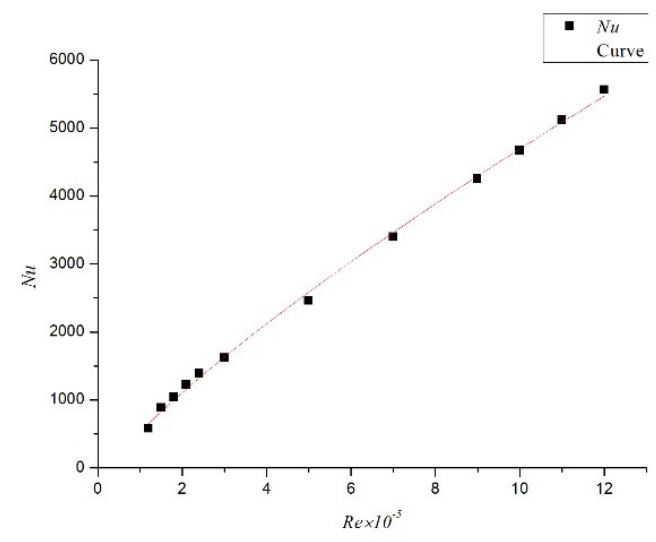

Inspired by the Dittus-Boelter equation, which is widely used in pipe heat transfer calculation, a novel correlation for thermal performance in elliptical pipe is developed based on the numerical solutions. Adding the variables A and B to correct Dittus-Boelter equation as $N u=\left(\mathrm{A} R e^{0.8}+\mathrm{B}\right) \mathrm{Pr}^{0.4}$. Using origin software to process data fitting, $\mathrm{A}$ and $\mathrm{B}$ can be obtained as $\mathrm{A}=0.02979$ and $\mathrm{B}=-8.5626$; the correlation coefficient is 0.99925 , which indicates that and the fit is very good as can be seen in Figure 7.

Therefore, the turbulent heat transfer experiment in the elliptical tube with axis ratio of 1.5 is related to the following formula:

$$
\begin{aligned}
& N u=\left(0.02979 R e^{0.8}-8.5626\right) P r^{0.4} \\
& R e \in\left(10^{4}, 1.2 \times 10^{5}\right)
\end{aligned}
$$

In this paper, liquid water is used as the working fluid, but Eq. (17) is designed to be suitable for all working fluids because all the results are based on the non-dimensional results. Therefore, the simulation used air as working fluid is proposed to validate the Eq. (17), seen in Table 3.

Table 3 The relative relationship between $N u$ number obtained by new formula and simulation in elliptical tube

\begin{tabular}{|c|c|c|c|}
\hline \multirow{2}{*}{$R e$} & \multicolumn{2}{|c|}{$N u$} & Deviation \\
\cline { 2 - 3 } & Eq. (17) & Simulation & $(\%)$ \\
\hline $1.2 \times 10^{4}$ & 37.2 & 39.0 & 4.8 \\
\hline $2.4 \times 10^{4}$ & 70.0 & 71.3 & 1.9 \\
\hline $4.7 \times 10^{4}$ & 127.0 & 125.3 & -1.3 \\
\hline $5.9 \times 10^{4}$ & 153.2 & 160.1 & 4.5 \\
\hline $7.9 \times 10^{4}$ & 194.7 & 201.5 & 3.5 \\
\hline $9.9 \times 10^{4}$ & 234.1 & 237.9 & 1.6 \\
\hline $1.2 \times 10^{5}$ & 271.9 & 276.6 & 1.7 \\
\hline
\end{tabular}

As can be seen from Table 3, the maximum deviation between the $\mathrm{Nu}$ obtained by Eq. (17) and simulation used air as working fluid is $4.8 \%$. Nitrogen and other working fluids are also simulated, and the maximum deviation is less than 5\%. Therefore, Eq. (17) is enough to precisely calculate the turbulent convection heat transfer intensity in elliptical tube.

Considering the effect of the axis ratio $a / b$ on the heat transfer effect of the elliptical tube, and introducing coefficient $\mathrm{C}$.

$$
\begin{aligned}
& N u=C\left(0.02979 R e^{0.8}-8.5626\right) P r^{0.4} \\
& R e \in\left(10^{4}, 1.2 \times 10^{5}\right)
\end{aligned}
$$
Table 4

Fit the data in Table 2 and get the coefficient $C$, as shown in the

Table 4 Coefficient $\mathrm{C}$ corresponding different $\mathrm{a} / \mathrm{b}$

\begin{tabular}{|c|c|c|c|c|}
\hline $\mathrm{a} / \mathrm{b}$ & 1.5 & 2 & 2.5 & $\geq 3$ \\
\hline $\mathrm{C}$ & 1 & 1.27 & 1.17 & 0.94 \\
\hline
\end{tabular}

Dittus-Boelter equation is valid for $R e$ ranging from $10^{4}$ to $1.2 \times 10^{5}$, but the realistic working conditions may exceed this limit. Therefore, the numerical simulation of twelve operation conditions which Re changes from $1.2 \times 10^{5}$ to $1.2 \times 10^{6}$ is presented, seen as Table 5. Using origin software to process the data in Table 5 and fit the formula, the correlation coefficient is 0.99925 once again and the fit is very good as seen in Figure 8.

$$
\begin{aligned}
& N u=C\left(0.03601 \operatorname{Re}^{0.8}-116.85088\right) \operatorname{Pr}^{0.4} \\
& R e \in\left(1.2 \times 10^{5}, 1.2 \times 10^{6}\right)
\end{aligned}
$$

Fig. 7 Fitting function curve 
Table 5 The deviation between $N u$ numbers obtained by Dittus-Boelter equation and by simulation in elliptic tube

\begin{tabular}{|c|c|c|c|}
\hline \multirow{2}{*}{$R e$} & \multicolumn{2}{|c|}{$\mathrm{Nu}$} & \multirow[b]{2}{*}{$\begin{array}{c}\text { Deviation } \\
(\%)\end{array}$} \\
\hline & Simulation & $\begin{array}{c}\text { Dittus- } \\
\text { Boelter } \\
\text { equation }\end{array}$ & \\
\hline $1.2 \times 10^{5}$ & 579.6 & 744.2 & 28.4 \\
\hline $1.5 \times 10^{5}$ & 889.7 & 692.9 & 28.5 \\
\hline $1.8 \times 10^{5}$ & 1039.2 & 801.7 & 29.6 \\
\hline $2.1 \times 10^{5}$ & 1220.5 & 907.0 & 34.6 \\
\hline $2.4 \times 10^{5}$ & 1390.2 & 1009.2 & 37.8 \\
\hline $3 \times 10^{5}$ & 1623.0 & 1206.5 & 34.5 \\
\hline $5 \times 10^{5}$ & 2459.4 & 1815.5 & 35.5 \\
\hline $7 \times 10^{5}$ & 3397.1 & 2376.3 & 43.0 \\
\hline $9 \times 10^{5}$ & 4255.7 & 2905.5 & 46.5 \\
\hline $1 \times 10^{6}$ & 4675.7 & 3161.0 & 47.9 \\
\hline $1.1 \times 10^{6}$ & 5117.8 & 3411.4 & 50.0 \\
\hline $1.2 \times 10^{6}$ & 5561.1 & 3657.3 & 52.1 \\
\hline
\end{tabular}

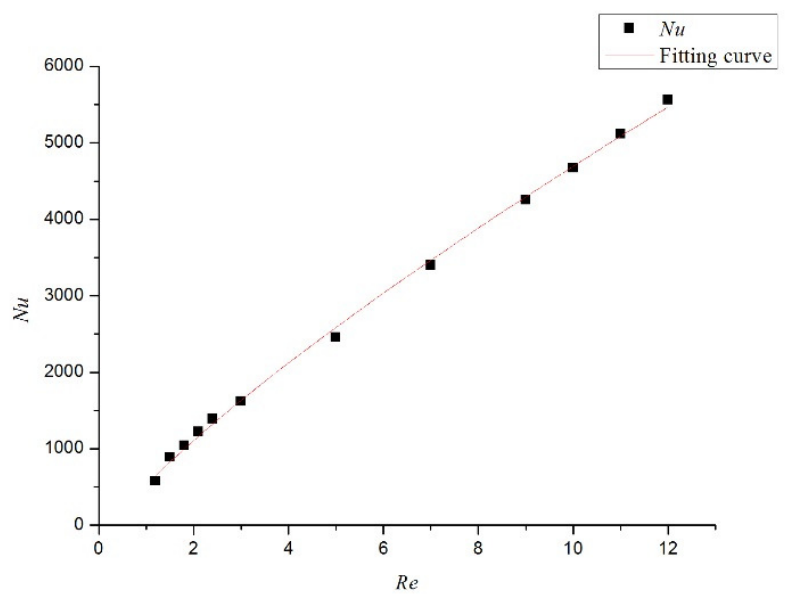

Fig. 8 Fitting function curve

\section{CONCLUSIONS}

In this paper, the turbulent convective heat transfer in elliptic tubes is studied by numerical simulation. From this investigation, some main conclusions can be summarized as follows:

(1) The numerical simulation results for the convection heat transfer in circular tubes are consistent with the Dittus-Boelter equation, indicating that the numerical calculation is reliable.

(2) The deviation is very large using the Dittus-Boelter equation with hydraulic diameter to calculate turbulent convective heat transfer in elliptical tubes. The maximum relative deviation is $28.4 \%$. Based on simulation results, the empirical correlation of turbulent convective heat transfer in an elliptical tube was obtained as follows:

$N u=C\left(0.02979 R e^{0.8}-8.5626\right) P r^{0.4}, R e \in\left(10^{4}, 1.2 \times 10^{5}\right)$

$N u=C\left(0.03601 \operatorname{Re}^{0.8}-116.85088\right) \operatorname{Pr}^{0.4}, \operatorname{Re} \in\left(1.2 \times 10^{5}, 1.2 \times 10^{6}\right)$

$(\mathrm{a} / \mathrm{b}=1.5, \mathrm{C}=1 ; \mathrm{a} / \mathrm{b}=2, \mathrm{C}=1.27 ; \mathrm{a} / \mathrm{b}=2.5, \mathrm{C}=1.17 ; \mathrm{a} / \mathrm{b} \geq 3, \mathrm{C}=0.94$. $)$

\section{ACKNOWLEDGEMENTS}

This work is supported by Chinese National Natural Science Foundation under Grants 51736007, 51476103.

\section{REFERENCES}

Aly, A. M. M., Trupp, A. C., Gerrard, A. D., 2006, "Measurements and Prediction of Fully Developed Turbulent Flow in an Equilateral Triangular Duct," Journal of Fluid Mechanics, 85(1), 57-83. https://doi.org/10.1017/S0022112078000531

Barrow, H., Hassam, A.K.A., 1985, "Heat Transfer in the Corners of Noncircular Ducts with Peripherally Uniform Wall Heat Flux," International Journal of Heat and Mass Transfer, 28(4), 895-896. https://doi.org/10.1016/0017-9310(85)90242-X

Batra, R.L., Koshy, K., 1979, "Numerical Solution of ThreeDimensional Entrance Flow of a Bingham Material through Noncircular Ducts," Computer Methods in Applied Mechanics \& Engineering, 19(3), 313-332.

https://doi.org/10.1016/0045-7825(79)90062-8

Chiappini, D., 2017, "Numerical Simulation of Natural Convection in Open-Cells Metal Foams," International Journal of Heat and Mass Transfer, 117, 527-537. https://doi.org/10.1016/j.ijheatmasstransfer.2017.10.022

Carrillo, J.A., Ranetbauer, H., Wolfram, MT., 2016, "Numerical Simulation of Nonlinear Continuity Equations by Evolving Diffeomorphisms," Journal of Computational Physics, 327, 186-202. https://doi.org/10.1016/j.jcp.2016.09.040

Colombo L.P.M., Lucchini, A., Muzzio, A., 2015, "Fully Developed Laminar Mixed Convection in Uniformly Heated Horizontal Annular Ducts," International Journal of Thermal Sciences, 94, 204-220. https://doi.org/10.1016/j.ijthermalsci.2015.03.008

Eckert, E.R.G., Irvine T.F., Jr, 1960, "Pressure Drop and Heat Transfer in a Duct with Triangular Cross Section," Journal of Heat Transfer, 82(2), 125-136.

https://doi.org/10.1115/1.3679891

Hermany, L., Lorenzini, G., Klein, R.J., Zinani, F.F., dos Santos, E.D., Isolid, L.A., Rocha, L.A.O., 2018, "Constructal Design Applied to Elliptic Tubes in Convective Heat Transfer Cross-Flow of Viscoplastic Fluids," International Journal of Heat and Mass Transfer, 116, 10541063.

https://doi.org/10.1016/j.ijheatmasstransfer.2017.09.108

Ibrahim, T.A., Gomaa, A., 2009, "Thermal Performance Criteria of Elliptic Tube Bundle in Crossflow," International Journal of Thermal Sciences, 48(11), 2148-2158.

https://doi.org/10.1016/j.ijthermalsci.2009.03.011

Li, Z., Yang, M., Zhang, Y., 2015, "Numerical Simulation of Melting Problems Using the Lattice Boltzmann Method with the Interfacial Tracking Method," Numerical Heat Transfer, Part A: Application, 68(11), 1175-1197.

https://doi.org/10.1080/10407782.2015.1037126

Li, Z., Yang, M., Zhang, Y., 2016, "Lattice Boltzmann Method Simulation of 3-D Natural Convection with Double MRT Model," International Journal of Heat and Mass Transfer, 94, 222-238. https://doi.org/10.1016/j.ijheatmasstransfer.2015.11.042 
Ma, X., Yang, M., Zhang, Y., 2016, “Analysis of Combustion Mechanism and Combustion Optimization of a 300MW Pulverized Coal Boiler," Frontiers in Heat \& Mass Transfer, 7(1).

http://dx.doi.org/10.5098/hmt.7.36

Malák, J., Hejna, J., Schmid, J., 1975, "Pressure Losses and Heat Transfer in Non-Circular Channels with Hydraulically Smooth Walls," International Journal of Heat and Mass Transfer, 18(1), 139-149. https://doi.org/10.1016/0017-9310(75)90016-2

Omara, M.A, Abdelatied, M.A, 2018, "Experimental Study of Heat Transfer and Friction Factor inside Elliptic Tube Fixed with Felical Coils," Applied Thermal Engineering, 134, 407-418.

https://doi.org/10.1016/j.applthermaleng.2018.02.017

Paweł Ocłoń, Stanisław Łopata, Kamil Chłosta, 2016, "Experimental and Numerical Investigation of Flow Distribution within the Heat Exchanger with Elliptical Tubes," Procedia Engineering, 157, 428-435.

https://doi.org/10.1016/j.proeng.2016.08.386

Peng, C., Geneva, N., Guo, Z., Wang, L.P., 2017, "Direct Numerical Simulation of Turbulent Pipe Flow Using the Lattice Boltzmann Method," Journal of Computational Physics, 357, 16-42. https://doi.org/10.1016/j.jcp.2017.11.040
Qiu, G., Yang, M., Wang, J., Zhang, Y., 2018, “Double Diffusive Natural Convection with Low-Pr Fluids with Soret and Dufour Effects," Frontiers in Heat \& Mass Transfer, 10(24).

http://dx.doi.org/10.5098/hmt.10.24

Ragued, H., Mansouri, K., 2013, "A Numerical Study of Viscous Dissipation Effect on Non-Newtonian Fluid Flow inside Elliptical Duct,"

Energy Conversion \& Management, 68(68), 124-132. https://doi.org/10.1016/j.enconman.2012.12.031

Terukazu, O., Hideya, N., Yukiyasu, T., 1984, "Heat Transfer and Flow around an Elliptic Cylinder," International Journal of Heat and Mass Transfer, 27(10), 1771-1779. https://doi.org/10.1016/0017-9310(84)90159-5

Yang, M., Ding, Z., Lou, Q., Wang, Z., Zhang, Y., 2017, "Lattice Boltzmann Method Simulation of Transient Natural Convection Heat Transfer in Horizontal Annulus," Journal of Thermophysics \& Heat Transfer, 31(3), 1-12.

https://doi.org/10.2514/1.T4978

Yang, M., Wang, P., Zhang, Y., Wang, Z., 2014, “A New Heat Transfer Correlation for Turbulent Flow of Air with Variable Properties in Noncircular Ducts," Journal of Heat Transfer, 136 (10) , 101701. https://doi.org/10.1115/1.4027855 